\title{
Investigating the Effect of Low Speed Impact on Sandwich Panel with Metal Foam Core (Comparing the Results of MATLAB and Abacus Analysis)
}

\author{
Hamed Farhadi Nai \\ Razi University, Kermanshah, Iran.
}

To Cite this Article

Hamed Farhadi Nai, "Investigating the Effect of Low Speed Impact on Sandwich Panel with Metal Foam Core (Comparing the Results of MATLAB and Abacus Analysis)", International Journal for Modern Trends in Science and Technology, Vol. 06, Issue 05, May 2020, pp.: 45-52; https://doi.org/10.46501/IJMTST060508

\section{Article Info}

Received on 12-March-2020, Revised on 24-April-2020, Accepted on 29-April-2020, Published on 01-May-2020.

\section{ABSTRACT}

In this paper, analytical modeling and numerical simulation of sandwich panel behavior with metal foam core under low impact impact are presented and how the formation and development of impact defects in impact loading conditions in three samples with different face sizes Taken, checked. Multi-layer sandwich panels are made of epoxy carbon and the core is also made of metal foam. Analytical modeling of low speed shock load on sandwich panels, using mass model and two-degree free spring, has been used to calculate the contact force. The spring stiffness of the contact site, and the bending and shear spring stiffness of the sandwich panel are calculated, the values of which change over time. To solve the equations of motion, the exact solution method has been used and the radius of the affected area is calculated using energy equations. In the next section, simulation of low speed impact on sandwich panels with metal foam core is done in three samples of different sizes in Abacus software, so that we see how to create and develop defects in sandwich panels. In the next section, we have examined the results and compared the numerical solution and analytical simulation, which confirms the process of research and this has been proven to be important.

KEYWORDS: sandwich panel, low speed shock, metal foam, defect development

Copyright (C) 2014-2020 International Journal for Modern Trends in Science and Technology, All rights reserved. DOI: https://doi.org/10.46501/IJMTST060508

\section{INTRODUCTION}

In recent years, given the importance of optimizing fuel consumption, increasing the safety and speed of vehicles such as aircraft, helicopters, UAVs and other vehicles such as cars, trains, ships, as well as increasing the strength of their bodies, special attention is paid to the structure of bodies. These devices have become. Therefore, many efforts to achieve and apply up-to-date and diverse technologies in the construction of panels required in these areas has become one of the challenging issues in the scientific and industrial societies of the world. Due to the importance and necessity of the process of lightening structures and objects used in important industries such as aerospace, the design and manufacture of composite materials for use in these industries is inevitable. For this reason, sandwich panels are mentioned as one of the most widely used materials in various structures, which is also used in Iran to develop various industries. For this purpose, this study analyzed sandwich panels with metal foam core and impact composite procedures [6]. 


\section{Analytical modeling with Matlab software}

Table 1: Geometric and mechanical specifications of sandwich panels

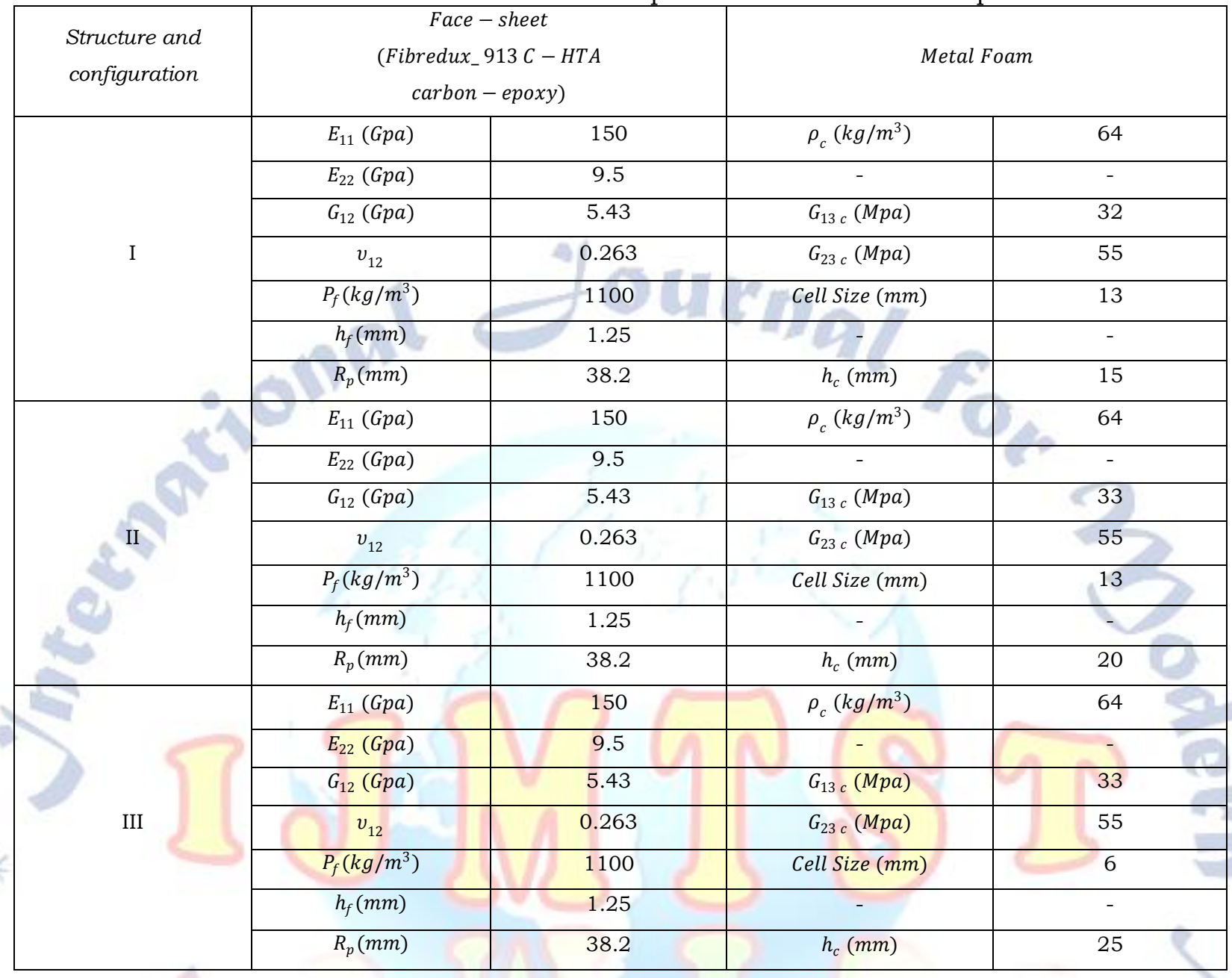

According to Table 1, in configuration I, the core thickness is $15 \mathrm{~mm}$ and the sandwich panel is exposed to the initial impact energy of 1.8 joules. In configurations II and III, the core thickness is 20 $\mathrm{mm}$ and $25 \mathrm{~mm}$, respectively, and they are exposed to the impact energy of 3.6 joules. Table 2 shows the impact energy and velocity of each configuration.

Table 2: Energy and impact speed in three different configurations of sandwich panels used

\begin{tabular}{|c|c|c|}
\hline \multicolumn{1}{|c|}{$\begin{array}{c}\text { Impact speed } \\
\text { (meters per } \\
\text { second) }\end{array}$} & $\begin{array}{c}\text { Impact Energy } \\
\text { (Jules) }\end{array}$ & $\begin{array}{c}\text { Sandwich panel } \\
\text { structure }\end{array}$ \\
\hline 1.18 & 1.8 & I \\
\hline 1.65 & 3.6 & II \\
\hline 1.65 & 3.6 & III \\
\hline 1.65 & 3.6 & \\
\hline
\end{tabular}

Now that we have the relationships presented in Chapter 3 , as well as the specifications and values of the different structures for the sandwich panel, we present the results of the impact simulation in all three different modes (scenarios).

\section{Case 1: $15 \mathrm{~mm}$ core thickness and impact rate}

\section{$1.18 \mathrm{~m} / \mathrm{s}$}

Figure 1 shows the contact force changes on the panel at different times. According to Figure 1, the incremental trend is somewhat reduced in about a second $2 \times 10^{-3}$, which is true when the force reaches the core of the metal foam and is resistant to change. This resistance returned to its previous state after about a second $1.3 \times 10^{-3}$ and the upward trend continued until the end.

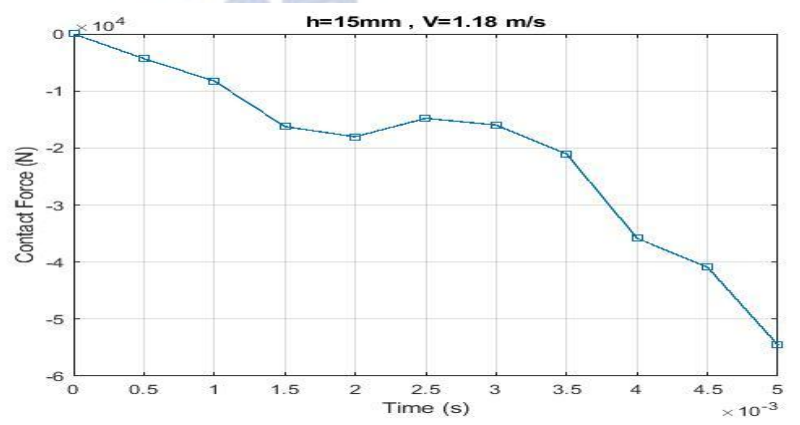

Figure 1: Contact force changes over time for the first mode 
Figure 2 shows the shift of the composite sheet relative to the increase in the force of the bullet. As can be seen, as the force increases, so does the displacement. But the important point in this form is that the slope of the increase is not the same. The reason for this is the resistance of the metal metal core to displacement and the change in the state of the composite panel. So that when the contact force is about $152 \mathrm{kN}$, the displacement of the sheet is equal to $6 \mathrm{~mm}$.

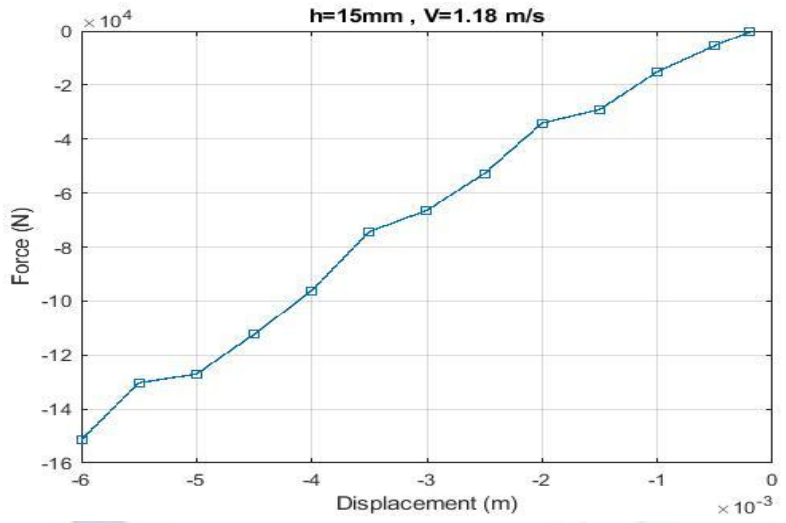

Figure 2: Changes in sheet displacement relative to force for the first case

In the next section, we examine the results of the second case, in which the thickness of the core and the impact velocity are increased.

\section{Case 2: $20 \mathrm{~mm}$ core thickness and impact rate}

\section{$1.65 \mathrm{~m} \mathrm{/} \mathrm{s}$}

Figure 3 shows the changes in contact force over time for the second case. As can be seen, with increasing speed, the core resistance also decreased and the slope of the increase increased compared to the previous state.

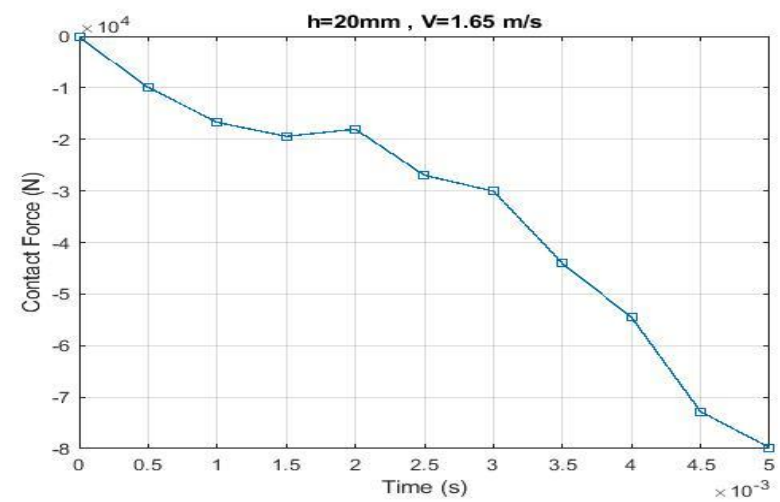

Figure 3: Contact force changes over time for the second mode

Comparing the results of the contact force changes in the first and second modes, it is observed that the impact speed has a significant effect on the changes in the sandwich panel. As can be seen, by changing the speed from $1.18 \mathrm{~m} / \mathrm{s}$ to $1.65 \mathrm{~m} / \mathrm{s}$, the contact force of the bullet and the sandwich panel in time $5 \times 10^{-3}$ Seconds increased from $53 \mathrm{KN}$ to about $80 \mathrm{KN}$.

The effect of increasing the thickness of the foam metal core can be seen in Figure 4. In this figure, the displacement changes relative to the force are shown. Comparing Figures 2 and 4, where the core thickness increased from $15 \mathrm{~mm}$ to $20 \mathrm{~mm}$, the displacement of the composite sheet also decreased, indicating the effect of the thickness of the metallurgy core on improving the performance of the composite panel.

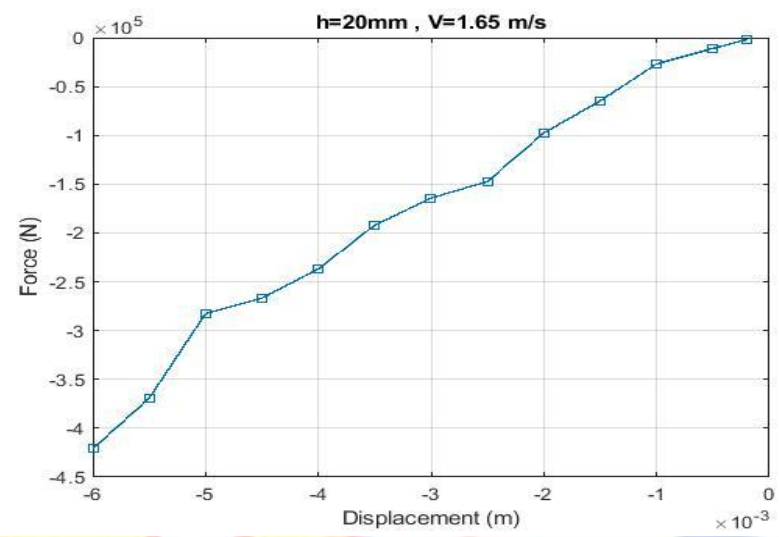

Figure 4: Changes in sheet displacement relative to force for the second case

In the following, we will examine the results of force changes with respect to time and displacement of composite sheets in the third case. In this case, the striking speed is equal to the second state, but we have increased the thickness of the metallurgy core from $20 \mathrm{~mm}$ to $25 \mathrm{~mm}$. The results are presented in Figures 5 and 6.

Third mode: core thickness of $30 \mathrm{~mm}$ and impact rate of $1.65 \mathrm{~m} / \mathrm{s}$

Figure 5 shows the contact force changes for the composite panel with the third type structure. As can be seen in this figure, increasing the thickness has a significant effect and its increasing trend per second1.5 $\times 10^{-3}$ The seconds have stopped. In fact, increasing the thickness of the metallurgy core has made it more resistant and resistant to contact force. Comparing this figure and Figures 1 and 3, it can be seen that aboutt $5 \times 10^{-3}$ Seconds later, the core of the new composite structure has taken action sooner and has shown resistance. 


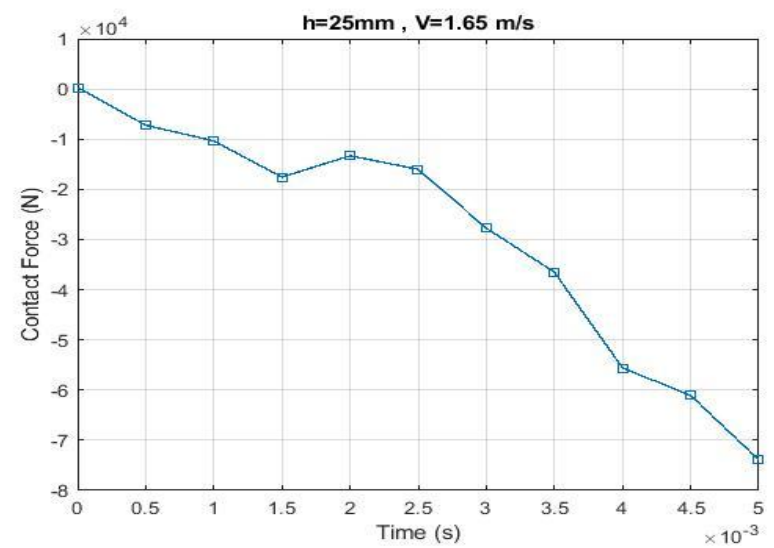

Figure 5: Contact force changes over time for the third mode

Figure 6 shows the shift in the composite sheet relative to the increase in force. Based on this figure and its comparison with Figure 4, it can be seen that increasing the core thickness under the same impact velocity conditions had a direct effect on reducing the displacement of the composite sheet after the impact of the bullet.

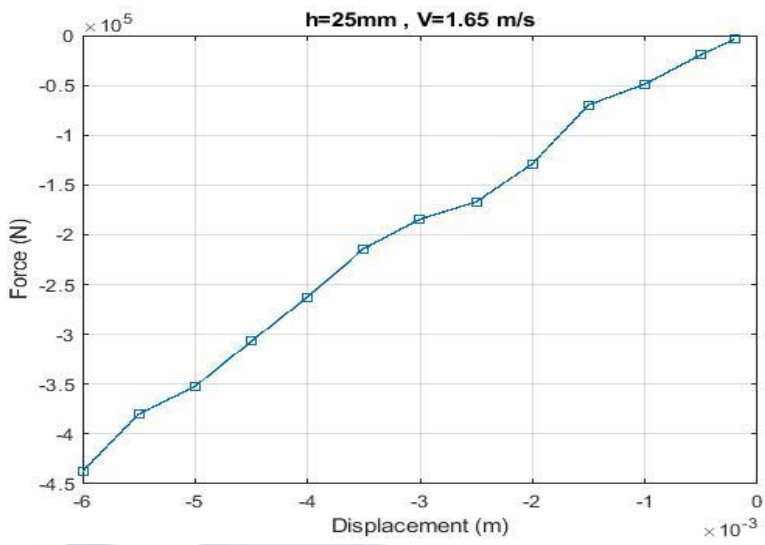

Figure 6: Changes in the displacement of the sheet relative to the force for the third case

\section{ANALYSis RESUltS In AbacUs SOFTWARE}

Analysis results 1: core thickness of $15 \mathrm{~mm}$ and impact rate of $1.18 \mathrm{~m} / \mathrm{s}$

Figures 7 and 8 show the damaged image from the sandwich panel, Figure 7 shows the image with the shock absorber, and Figure 20 shows the image without the presence of the shock absorber and the damaged location. As can be seen from the figures, when the striker hits the sandwich panel, the top and bottom sheets separate from the core and damage to both pieces, the composite sheets and the metallic core.

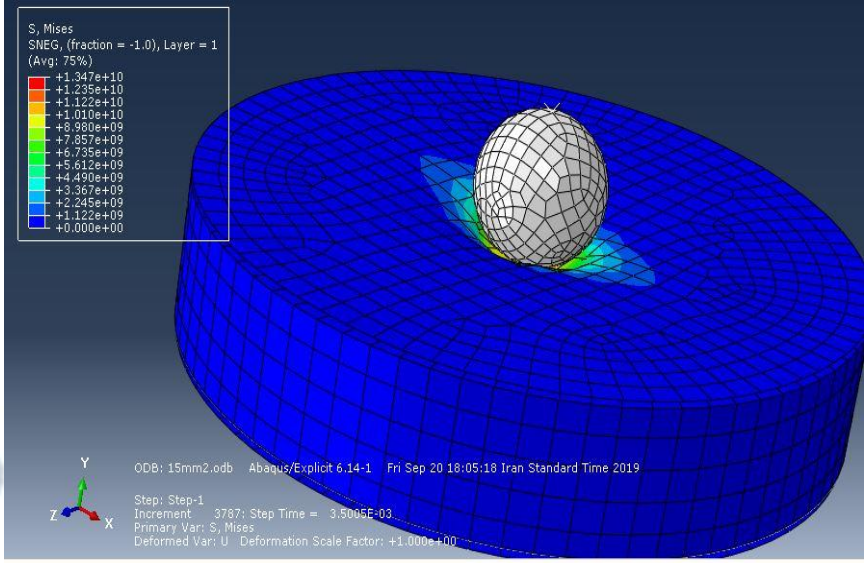

Figure 7: Image of damaged sandwich panel

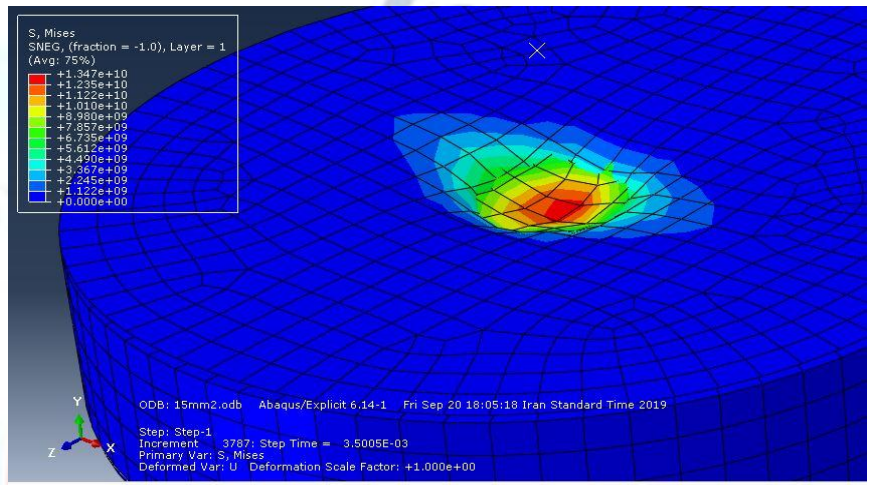

Figure 8: Image of the impact site of the impact sandwich on the sandwich panel

Figure 9 shows the contact force applied to the sandwich panel. As can be seen from the figure, the contact force has increased over time. At 0.002 seconds after the start of the analysis, this increase in contact force increases at a slower rate, which can be due to the surrender of the composite sheet and the arrival of the force to the metal foam core, which in itself has more strength and durability.

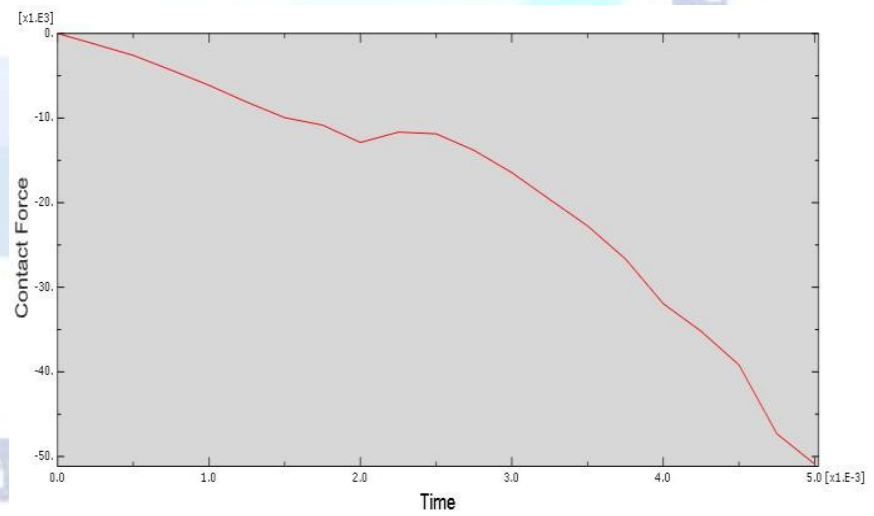

Figure 9: Contact force by time

After hitting the impact, the kinetic energy increases more and more over time, while initially this increase increases at a slower rate and over time at a much faster rate, and this seems obvious, because over time the force increases. Saved to damage the sandwich is stored as a strain energy 
in the sandwich. In Figure 22, the diagram shows the amount of displacement and deformation of the sandwich panel per imported force.

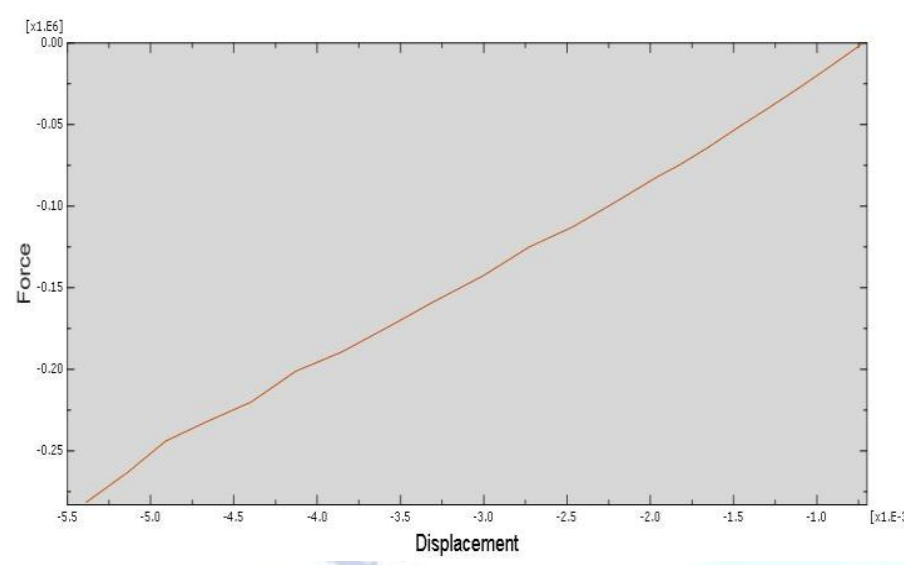

Figure 10: Force displacement diagram

\section{Results of analysis 2: core thickness $20 \mathrm{~mm}$ and} shock speed $1.65 \mathrm{~m} / \mathrm{s}$

Figures 11 and 12 show the damaged image from the sandwich panel, Figure 11 shows the image with the shock absorber, and Figure 24 shows the image without the presence of the shock absorber and the damaged area. As can be seen from the figures, when the striker hits the sandwich panel, the top and bottom sheets separate from the core and damage to both pieces, the composite sheets and the metallic core.

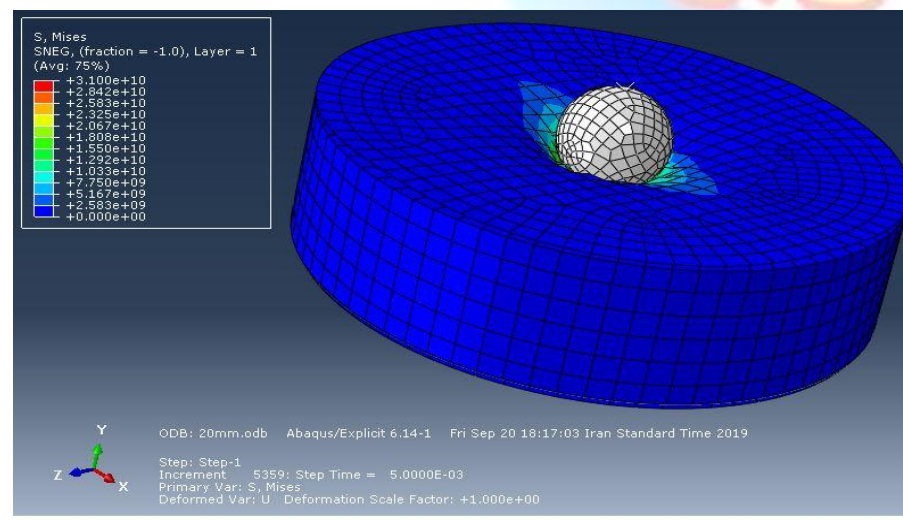

Figure 11: Image of damaged sandwich panel

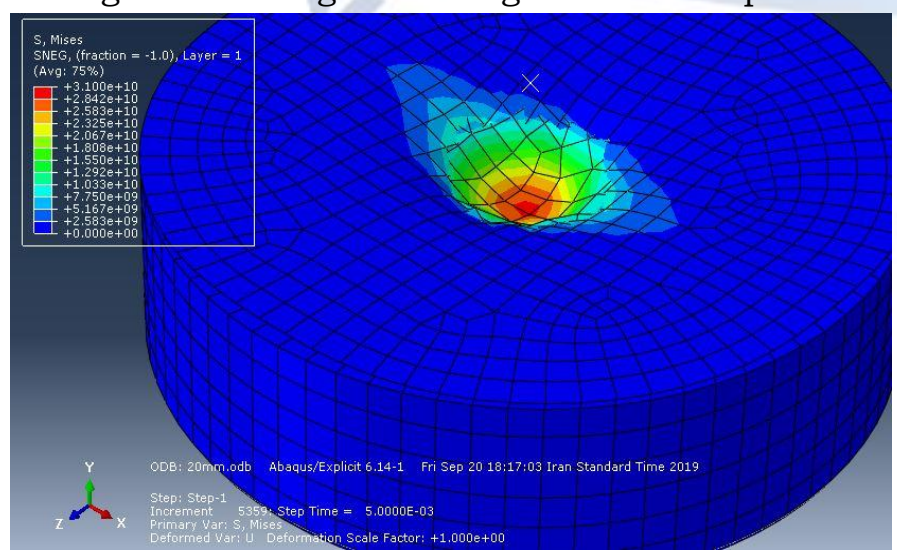

Figure 12: Image of the damaged sandwich panel

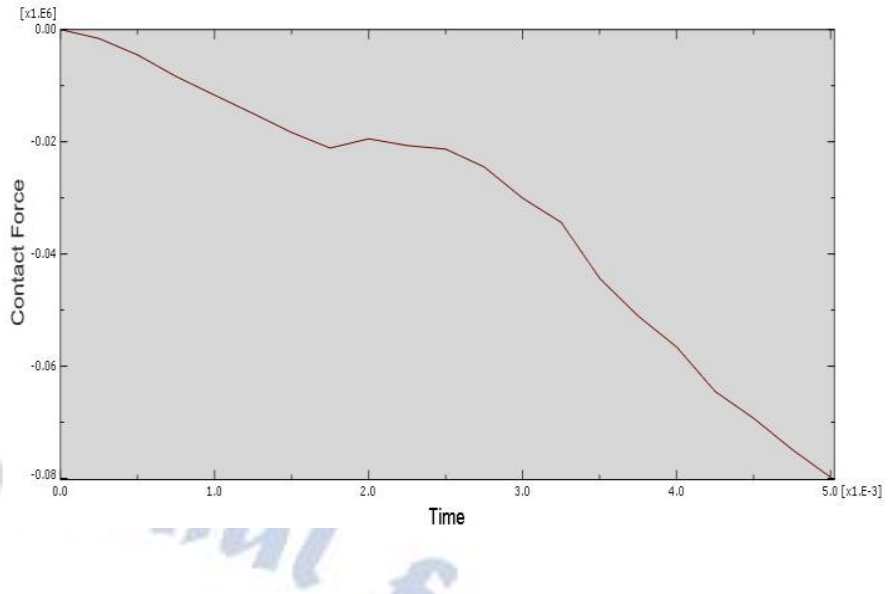

Figure 13: Contact power diagram in terms of time Figure 13 shows the contact force applied to the sandwich panel. As can be seen from the figure, the contact force has increased over time. At 0.002 seconds after the start of the analysis, this increase in contact force increases at a slower rate, which can be due to the surrender of the composite sheet and the arrival of the force to the metal foam core, which in itself has more strength and durability.

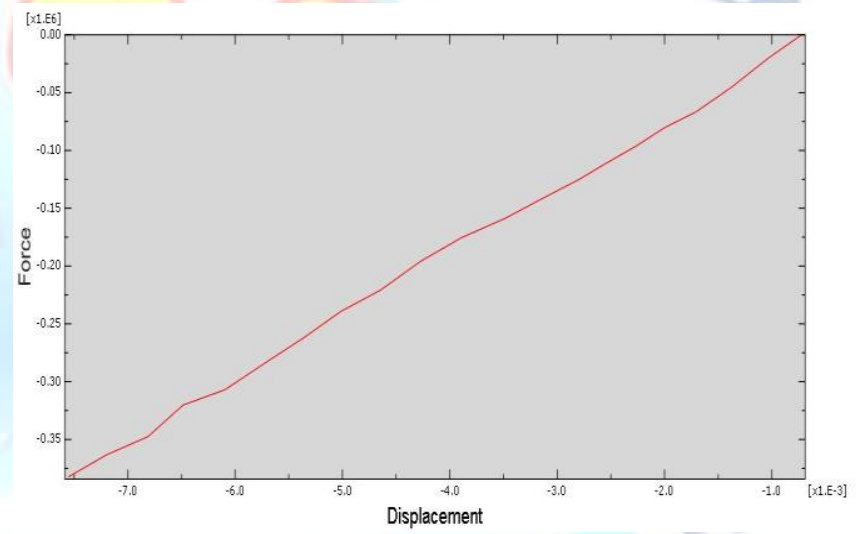

Figure 14 Force displacement diagram

Results of analysis 3: core thickness $25 \mathrm{~mm}$ and impact velocity $1.65 \mathrm{~m} / \mathrm{s}$

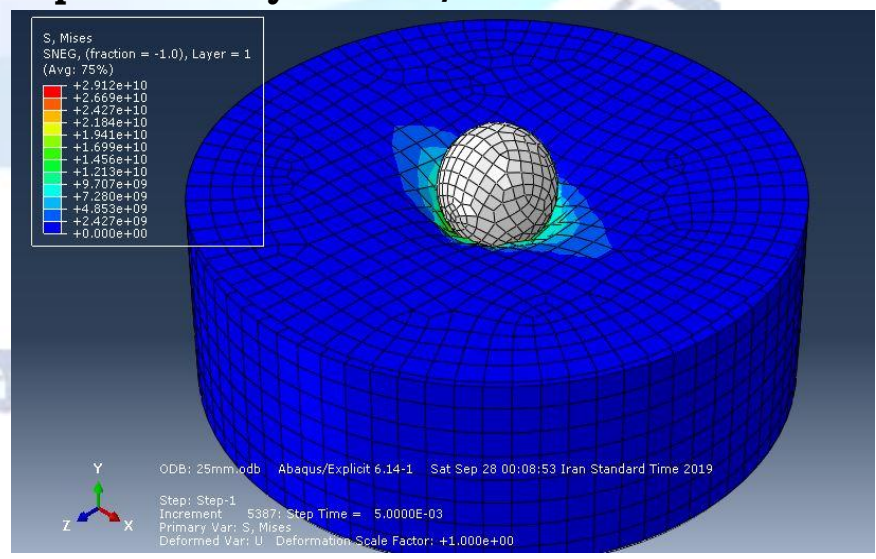

Figure 15: Image of the damaged area of the sandwich panel

Figures 15 and 16 show the damaged image of the sandwich panel, Figure 15 shows the image with 
the shock absorber, and Figure 16 shows the image without the presence of the shock absorber and the damaged area. As can be seen from the figures, the tractor and the core of the model were damaged when the striker hit the sandwich panel.

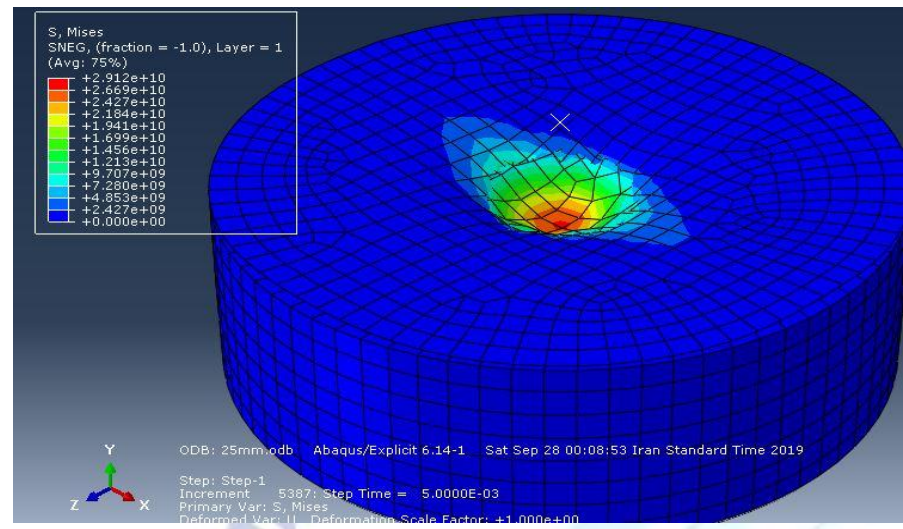

Figure 16: Damaged sandwich panel image

Figure 17 shows the contact force applied to the sandwich panel. As can be seen from the figure, the contact force has increased over time. At 0.002 seconds after the start of the analysis, this increase in contact force increases at a slower rate, which can be due to the surrender of the composite sheet and the arrival of the force to the metal foam core, which in itself has more strength and durability.

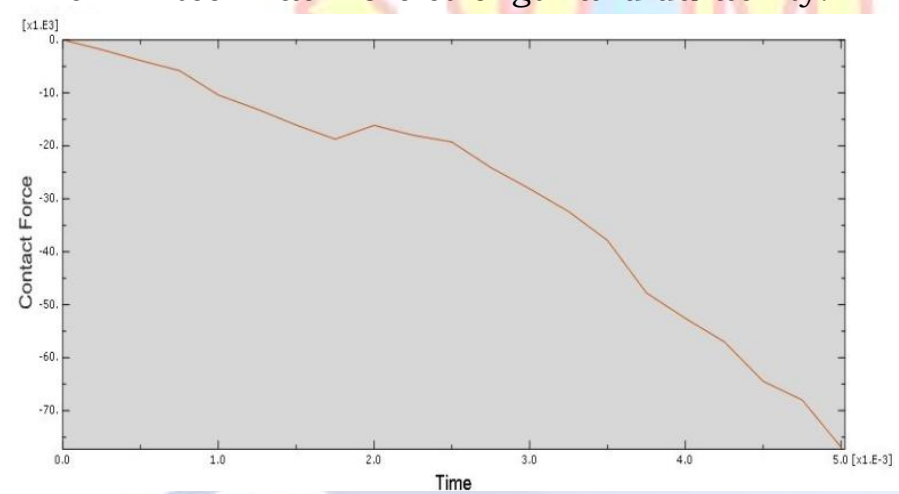

Figure 17: Time force diagram in terms of time

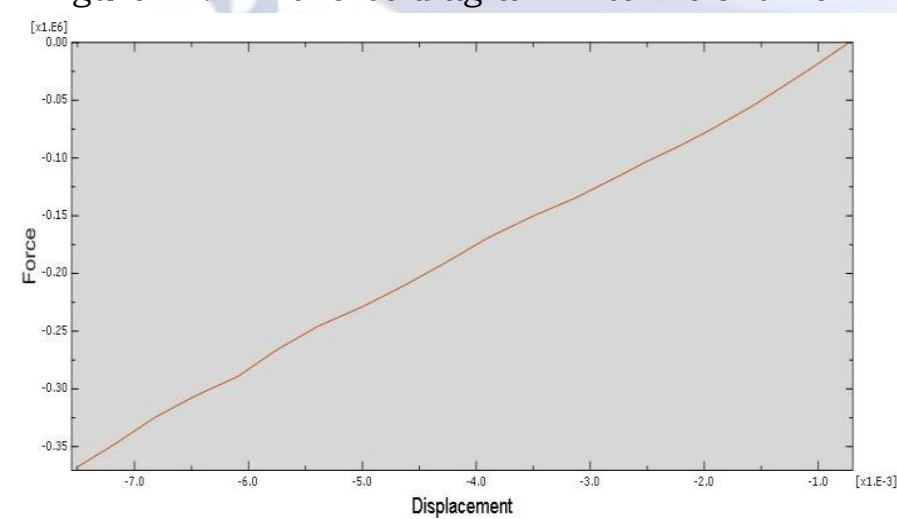

Figure 18: Force displacement diagram

\section{Conclusion}

Since one of the most practical problems of collision phenomenon is asynchronous impact to the structure, in this research, dynamic analysis of low-speed non-simultaneous impact on sandwich panel with metal-foam core has been performed. Other research in this area is often experimental, and the need for solutions using theoretical relations seems essential. It should also be noted that problem solving by theory can reduce test costs and, with the help of its results, provide an estimate of the test results. In this regard, in the present study, the results of the free fall test have been modeled using the theory method. Dynamic equations were obtained using Hamilton's principle, assuming classical theory and small deformation for Hertz's sheet and contact law. Using a dual February solution for simple support, the results of dynamic analysis are presented taking into account the independent components of time and place of collision. After validating and converging the answer, the most important results are as follows:

- In the fixed time interval between non-simultaneous beats, the spatial distance between the two shock absorbers, depending on the speed of propagation of the waves, has a direct effect on the structural or destructive interference of the interfering waves. As a result, all outputs are oscillating. If the wavelength between the collision sites is too long, the contact force and the amount of energy absorbed in each of the non-simultaneous shocks will be similar to the single-stroke mode.

- The collision time plays a key role in the structural / destructive interference of non-synchronous shock waves; therefore, the dynamic response of the structure is completely affected by this parameter. In other words, by changing the time interval between non-simultaneous beats, changes in all outputs do not have a predictable pattern.

- As the time interval between non-simultaneous strokes increases by a certain amount (at any fixed spatial distance), subsequent strokes will have no effect on the contact force and energy absorbed by the structure in previous strokes.

- The maximum contact force in the free fall test is obtained at the first impact and the frequency of vibrations increases with subsequent shocks.

\section{Comparison of MATLAB and Abacus results}

One of the things that has been done as a confirmation of the research is to compare the results of numerical solution (Abacus) and analytical solution (MATLAB). As stated at the beginning of the analytical solution, we have 
considered the simulation conditions in both applications to be the same so that a comparison can be made here between the results obtained from both analyzes. Therefore, we present the results of the changes in contact force over time for all three modes considered (collision velocity and core thickness) in Figures 19 to 21 .

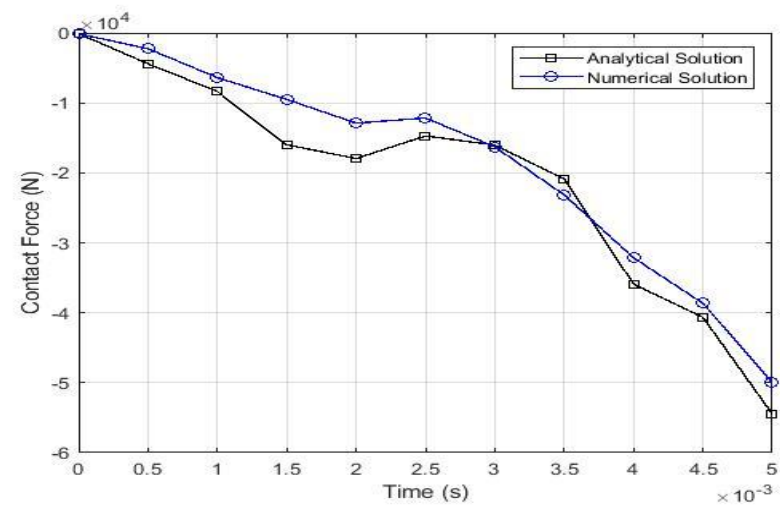

Figure 19: Comparison of changes in contact force of analytical solution and numerical solution for the first case

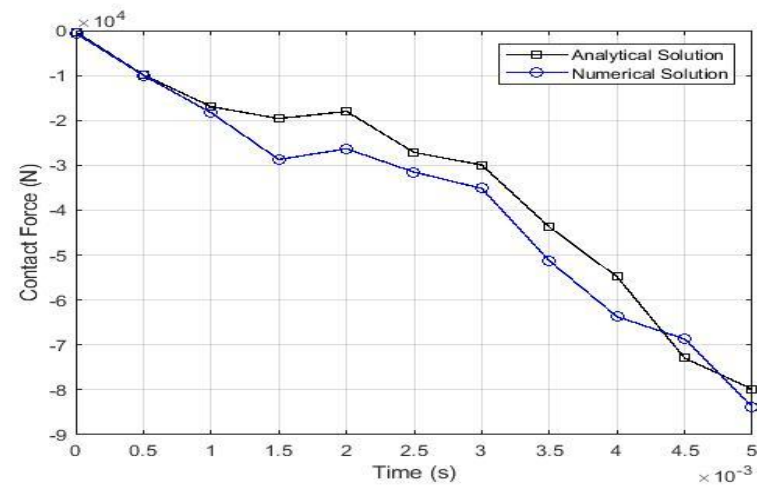

Figure 20: Comparison of changes in contact force of analytical solution and numerical solution for the second case

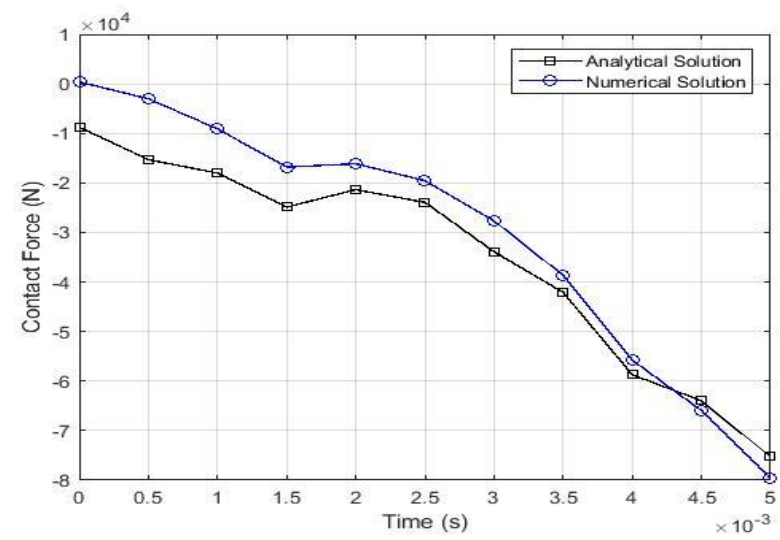

Figure 21: Comparison of changes in contact force of analytical solution and numerical solution for the third case

Based on what is seen in Figures 19 to 21, the difference between numerical and analytical solutions in the first case averages 8.21 percent, for the second case averages 9.24 percent, and for the third solution averages 9.89 percent. Given that the standard difference should be less than $10 \%$, it can be acknowledged that the difference is acceptable and the validation has been successful. Now, in order to compare these states with each other, we present Figure 22, which shows the comparison of the contact force with respect to time.

As can be seen, the third mode, in which the thickness of the metallized core is increased, has the best performance against the force applied to the composite bullet when it hits it.

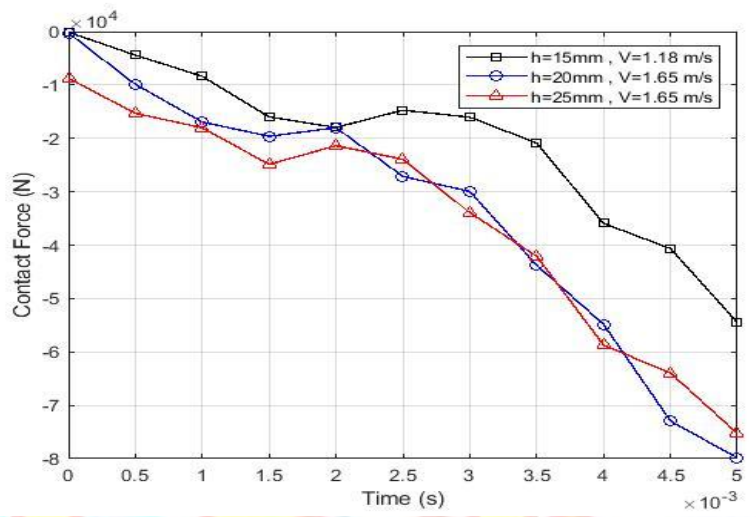

Figure 22: Comparison of changes in contact force

in all three cases using analytical solution

Figure 23 provides a comparison from the point of view of changes in the displacement of the composite sheet due to the increase in the force exerted by the bullet for all three modes considered. As can be seen, in cases where the projectile velocity is the same (second and third modes), increasing the thickness of the metal foil core prevents the increase in the displacement of the composite sheet.

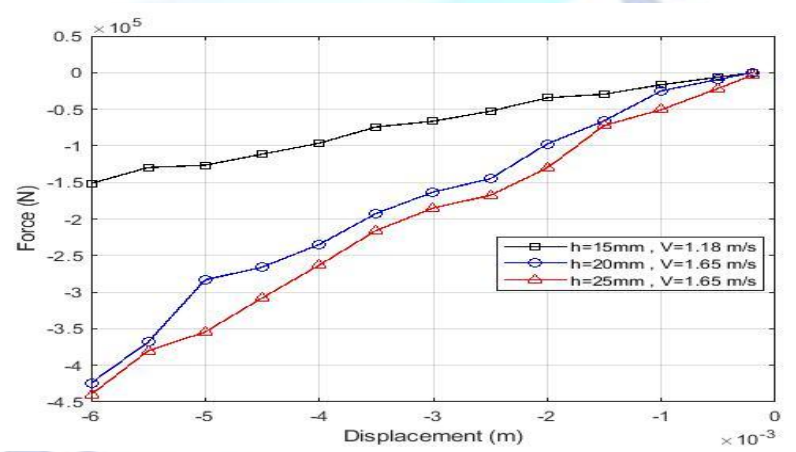

Figure 23 Comparison of sheet displacement changes with respect to force changes in all three cases using analytical solution

Looking at the figure above, it can be seen that, for example, when the projectile velocity is 1.65 meters per second, if the core thickness is $20 \mathrm{~mm}$, a force of about $234 \mathrm{KN}$ will result in a displacement of about $4 \mathrm{~mm}$. However, for this amount of 
displacement, $263 \mathrm{KN}$ is required in the case of core thickness of $25 \mathrm{~mm}$.

On the other hand, it is observed that the speed of the bullet and its impact with the composite sheet has a high impact on the displacement of the composite sheet. As the speed increases, so does the force of the impact, which is a reason to reduce the impact on the displacement of the composite sheet.

\section{REFERENCES}

[1] G. Lu and T. Yu., "Energy Absorption ofStructures and Materials",Cambridge, Wood head PublishingLtd, 2003.

[2] M. F. Ashby., "Metal foams: a design guide," Butterworth-Heinemann, 2000.

[3] M. S. Hoo Fatt, K. S. Park., "Perforation of honeycomb sandwich plates by projectiles," Composites part A: Applied Science and Manufacturing, Vol. 31, pp. 889-899, 2000.

[4] C. Lin, M. S. Hoo Fatt., "Perforation of sandwich panels with honeycomb cores by hemispherical nose projectiles," Journal of Sandwich Structure and Materials, Vol. 7(2), pp. 133-172, 2005.

[5] J. Kepler., "Impact penetration of sandwich panels at different velocities an experimental parameter study: Part I - Parameters and Results," Journal of Sandwich Structure and Materials, Vol. 6(5), pp. 357-374, 2004.

[6] J. Kepler., "Impact penetration of sandwich panels at different velocities an experimental parameter study: Part II - Interpretation of Results and Modeling," Journal of Sandwich Structure and Materials, Vol. 6(5), pp. 379-397, 2004.

[7] S. Feli, M. Namdari Pour., "An analytical model for composite sandwich panels with honeycomb core subjected to high-velocity impact," Composites Part B: Engineering, Vol. 43(5), pp. 2439-2447, 2012.

[8] R. Studziński, Z. Pozorski., "Experimental and numerical analysis of sandwich panels with hybrid core," Journal of Sandwich Structures \& Materials, Vol. 20(3), pp. 271-286, 2016..

[9] Ar Apurva Bose Dutta.,"Pre-engineered Building PEB System hit Indian construction market," MGS Architecture, May-June 2012.
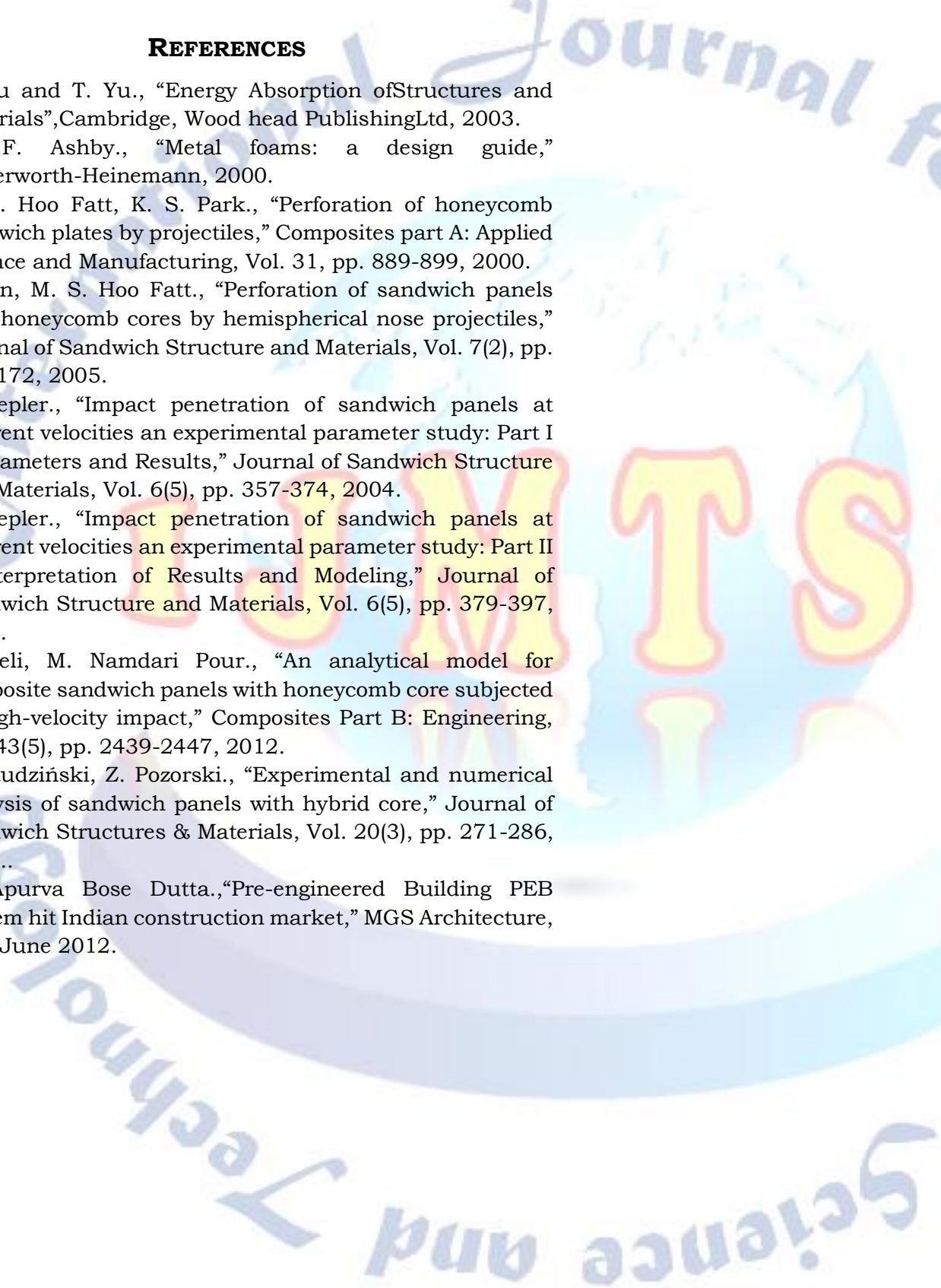